Área Abierta. Revista de comunicación

audiovisual y publicitaria

ISSN: 1578-8393 / ISSNe: 1578-8393

\title{
Hacer, explicar, enseñar cine. Didáctica y epistemología de la creación fílmica
}

\author{
José Ángel Lázaro López ${ }^{1}$
}

Recibido: 5 de marzo de 2018/ Aceptado: 14 de mayo de 2018

Resumen. La relación entre teoría y práctica en los estudios académicos cinematográficos sufre un estado de segregación y distanciamiento que es causa y efecto de una profunda crisis de entendimiento entre académicos y cineastas. Sin embargo, esta crisis no puede afrontarse, en primer lugar, desde la asunción de esa dicotomía intelectual entre el ellos y el nosotros —-desde dondequiera que se sitúe la otredad en el enfoque-, ni tampoco desde la observación de ningún conflicto radical entre ambos mundos profesionales del cine, ya que ese conflicto, al menos de forma manifiesta, no existe. ¿Qué perspectivas didáctica y epistémica genera esta situación de cara a los estudios fílmicos y cinematográficos? ¿Cómo se puede enseñar cine en estas circunstancias? En el presente artículo se analiza esta controvertida situación y se acentúa la necesidad de romper esta dicotomía para resituar el foco de atención en las condiciones necesarias y existentes para explicar y poder trascender, desde una perspectiva epistémica y sustancialmente didáctica, esa aparente distancia entre dos caras de una misma moneda que llamamos cine.

Palabras clave. proceso creativo; estudios fílmicos; teoría y práctica cinematográficas; enseñanza fílmica; cinematografía; escuelas de cine

\section{[en] Making, Explaining, Teaching Cinema. Didacticism and Epistemology of Film Creation}

\begin{abstract}
The relationship between theory and practice in academic film studies depicts a state of segregation and distancing which turns out to be, at the same time, cause and effect of a deep crisis of understanding between academics and film makers. Nevertheless, this crisis cannot be faced, in the first place, from the assumption of that intellectual dichotomy between them and we -wherever this otherness may be located in the approach-, neither from the observation of any radical conflict between both professional cinematographic environments, since that conflict, at least in an explicit manner, doesn't exist. What kind of epistemic or didactic perspectives bring this situation to the film and cinematographic studies? How can cinema be taught under these circumstances? In this article, we analyze this controversial situation and we stress the necessity of breaking that dichotomy to relocate the focus of attention onto the necessary and existing conditions to explain and to be able to transcend, under an epistemic and substantially didactic perspective, that apparent distance between two sides of the same coin we call cinema.
\end{abstract}

Key words. creative process; film studies; film theory and practice; film teaching; cinematography; film schools

1 Universidad Carlos III (España)

E-mail: jlazaro@hum.uc3m.es 
Sumario: 1. Introducción. 2. Nueva película, vieja teoría. 3. Praxis fílmica, lugar de encuentro. 4. Hacia el cine por el cine. 5. Ni ellos ni nosotros. Conclusiones a partir de un perfil. 6. Bibliografía

Cómo citar: Lázaro López, J.Á. (2018). Hacer, explicar, enseñar cine. Didáctica y epistemología de la creación fílmica, en Área Abierta. Revista de comunicación audiovisual y publicitaria 18 (3), 477-490. http://dx.doi.org/10.5209/ARAB.59422

\section{Introducción}

Hoy, más que nunca, una enorme cantidad de cineastas ${ }^{2}$, de todo estilo y perfil, practican la docencia sobre la creación fílmica en todo tipo de centros de formación dedicados al cine, ya sea en su vertiente más académica o desde una formación enfocada a la capacitación profesional práctica. Sin embargo, el corpus teórico académico sobre la creación fílmica no parece inmutarse ante esta labor, a la que estos mismos cineastas dedicados a la docencia no aportan material teórico alguno, y de la que no parecen alimentarse, ni a la hora de poner en práctica sus procesos de creación fílmica, ni a la de enseñar estos en sus clases. Por su parte, los académicos del campo audiovisual tampoco tienen, en general, una especial tendencia a teorizar sobre la especificidad de este proceso creativo, y centran su esfuerzos y atención en el objeto fílmico de la película terminada y en los entornos sociales, económicos y culturales del llamado "mundo del cine", sustentando sus obras al respecto sobre los aspectos históricos y teóricos arrojados del estudio de las películas que engrosan el canon oficial de la cinematografía clásica occidental.

Al mismo tiempo, en los centros universitarios, y después de más de cincuenta años desde la incorporación de los estudios sobre cine, las tendencias programáticas actuales han derivado claramente hacia el privilegio de los contenidos prácticos, y ambas perspectivas - teórica y práctica- se estudian completamente por separado, siendo incluso impartidas por diferentes grupos de profesores. Como señala Rafael Tranche, aún en la actualidad, el objeto film tiende a verse, incluso entre teóricos e historiadores, como un producto hermético que no permite percibir sus elementos constitutivos, y lo que es peor, como si dichos elementos no pudieran revelarnos aspectos esenciales de la concepción y los significados del mismo. En consecuencia, considera el autor que "cualquier intento de elucidar las claves formales o los procesos de sentido que operaron en su gestación y conforman su lectura final resulta

2 Utilizaremos en general el término "cineasta”, cuando no esté acompañado por adjetivo o aclaración alguna, para designar a los creadores cinematográficos, representantes del elemento práctico y fáctico de la ecuación, pero también en determinados momentos englobaremos en él a los teóricos del cine, si bien, en estos casos, encontraremos en la redacción del texto las aclaraciones necesarias para no incurrir en confusiones sobre la utilización general del término. 
sospechoso, o bien se reduce su explicación a pasos mecánicos, rutinas profesionales en las que solo puede ocurrir lo que previamente se ha planificado" (Tranche, 2015: 23).

¿Qué perspectivas didáctica y epistémica genera esta situación de cara a los estudios fílmicos y cinematográficos? ¿Cómo se puede enseñar cine en estas circunstancias? Para responder a estas dos preguntas hemos de incluir la doble perspectiva de la primera en la segunda. Reunir el "saber" y el "hacer" en un campo de estudio y de trabajo que parece estar aún por formarse.

Si comenzamos a observar detenidamente ese no lugar donde debieran de converger o convivir las dos perspectivas - hacer y saber, práctica y teoría一, la figura del académico inmerso en la observación del proceso creativo del cineasta nos puede resultar de utilidad. El profesor Luis Alonso, en sus notas de campo en el set sobre el proceso de creación del cineasta catalán Jaime Rosales, detecta el "carácter tácito de los conocimientos implicados en las veladas habilidades de los cineastas" (Alonso, 2013: 19). Partiendo del problema del artesano planteado por Sennett —la dificultad del creador para describir su labor (Sennett, 2009) - , podemos evidenciar que, en un terreno tan complejo y multidimensional como el del cine, las variables y los parámetros de trabajo que hemos de manejar no siempre responden, a la hora de ser explicados, a la capacidad de elocuencia que podemos esperar de otros ámbitos de estudio. Josep María Català reporta la apreciación al respecto de Víctor Erice en relación con una de las innegables materias expresivas fundamentales del cine: "cuando se me pregunta qué es el tiempo, no sé qué contestar, pero cuando no se me pregunta, como decía San Agustín, sí sé lo que es" (Ferrer et alii., 2006: 73). Esta suma entre incapacidad y disimulo hace del cineasta un objeto de estudio especialmente opaco y arduo de observar, y su proceso de creación un sistema de trabajo, en ocasiones, directamente oculto. Entre el "saber" y el "hacer" debemos situar por tanto una reflexión sobre el "hacer saber" y su necesario precedente, el "saber sobre el hacer". Y ahí es donde el cineasta que se acerca a la docencia parece rehusar a adaptarse a las reglas y rutinas del "saber sobre ese hacer", es decir, de la teoría sobre la creación fílmica que él/ella maneja dentro de un contexto profesional muy diferente al didáctico. ${ }^{3}$

Si repasamos la bibliografía habitual que se maneja actualmente en los centros universitarios alrededor de las asignaturas de dirección, realización y puesta en escena, encontramos un corpus de títulos claramente asentado: completando la revisión efectuada por Alonso (Alonso, 2013), podemos encontrar las introducciones generales, que dan un cierto peso - no demasiado- al proceso cinematográfico, entre las que la de Bordwell y Thompson (1979) es prácticamente fija en todos los compendios, y a la que pueden añadirse las de Costa (1985), Chion (1990) o Benet (1999); los manuales técnicos de realización y producción: de los orientados al proceso en su conjunto (Camino, 1997; Rabiger, 2003; Schenk y Long, 2012, y recientemente Ciller y Palacio (2016), a los enfocados en la planificación (Arijon, 1976; Katz, 2005; Brown, 2008; Català, 2001); y, finalmente, las poéticas o teorías de autor, de los aforismos de Bresson (1975) y las reflexiones de Tarkovski (2002) a

3 En esta aproximación, el extendido concepto del know-how se torna en una auténtica trampa que puede cortocircuitar el paso al marco de la práctica cinematográfica a la enseñanza de la misma, ya que de esa capacidad no se deriva la generación de conocimiento alguno que pueda ser teorizado y puesto a disposición del estudiante de cine. 
los libros de entrevistas, de Sarris (1967) a Tirard (2002, 2006). La mayor parte de esa bibliografía tiene en común (salvo los casos más personales como los de Bresson o Tarkovski) entender el cine como una simple aplicación mecanicista, con mayor o menor originalidad, de una supuesta gramática y sintaxis universal de la imagen y el sonido que mediaría neutral y naturalmente entre actores y espectadores (Alonso, 2013). Como ejemplo ilustrativo del reduccionismo que esta bibliografia destila sobre las posibilidades de la creación fílmica, podemos tomar uno de los manuales utilizados regularmente en el ámbito universitario, el de Steven Katz (2005). Según este, existen diez maneras de planificar un diálogo entre dos personajes plano a plano. Para explicar esta aseveración, el manual dedica sus siguientes veinte páginas y ochenta y siete fotografías a visualizar esas diez fórmulas de planificación. (Katz, 2005: 173-193). La decisiva intuición de Burch sobre la sustancialidad creativa del découpage está siendo dirigida, a través de este tipo de planteamientos didácticos, hacia su propio estrangulamiento.

Si observamos la problemática desde la tradicional óptica teórica de la comparación con otros oficios y artes expresivas, la visión no solo no facilita la tarea epistemológica, sino que, a pesar de existir ingentes cantidades de trabajos sobre los encuentros, desencuentros y características en común o en conflicto, esta trillada línea de investigación acaba por revelarse como reduccionista y limitada, no tanto por los aspectos tratados, sino por el propio enfoque que, aparte de fracasar en sus reiterados intentos por definir la naturaleza expresiva del cine en función de sus similitudes y préstamos con otras artes, desvía completamente la atención de la observación real del proceso de creación fílmica, y deviene incluso contraproducente en su aplicación didáctica para la formación cinematográfica. Centrados en las similitudes e influencias frente - fundamentalmente - al teatro, la pintura y la literatura, estos análisis obvian reiteradamente aspectos tan cruciales de la condición expresiva y creativa del cine como, por ejemplo, la música o la dirección de actores, así como el papel de estos en el proceso creativo de los cineastas, quedando limitados en su mayoría a una observación de los debates históricos sobre la naturaleza supuestamente bastarda y mestiza del cine. De entre los efectos instaurados en los estudios por este tipo de enfoques, el que más peso ejerce sobre el estado de la cuestión es, a nuestro juicio, el sometimiento de buena parte de los estudios sobre cine a la narrativa derivada de los estudios literarios, tanto en su perspectiva puramente analítica, como en la epistémica y - de crucial interés para nosotros- en la didáctica. A estas alturas, no podemos seguir conformándonos con la noción de puesta en escena difundida por Bordwell y Thompson, según la cual esta se limita a la recreación del suceso explicitado en el guion sin más (Bordwell y Thompson, 1995).

\section{Nueva película, vieja teoría}

Si, como sabemos, Christian Metz llegó a la conclusión de que el cine no era una lengua sino un lenguaje, quizá desde esa misma perspectiva podemos comenzar a liberarnos del yugo narratológico y pensar la naturaleza expresiva y comunicativa del cine de una forma más abstracta $\mathrm{y}$, al mismo tiempo, más ajustada a las verdaderas potencialidades expresivas del medio que, especialmente en elámbito docente, estamos pasando sistemáticamente por alto. Si hablar una lengua es emplearla basándonos en sus reglas preexistentes, utilizar el lenguaje cinematográfico supone siempre y hasta 
cierto punto inventarlo o reinventarlo, y esta circunstancia bien puede ser una de las características consustanciales de la creación fílmica. Como consecuencia de esta condición, las posibles explicaciones sobre los procesos de sistematización de la creación de cada película podrían entenderse como potencialmente obsoletos fuera del contexto de cada producción en particular. Quizá en esta necesaria obsolescencia artística - necesaria para poder adquirir esta misma naturaleza como arte- podemos empezar a comprender y tal vez explicar la renuencia y la dificultad que los cineastas encuentran para convertir en paradigma teórico la experiencia creativa fílmica.

Recordemos con Ernst Gombrich que, en una aproximación de este tipo, los conceptos no pueden ser verdaderos o falsos. Solo pueden ser más o menos útiles para la formación de descripciones (Gombrich, 1997: 110). En su investigación en busca de los fundamentos teóricos que se puedan derivar de las ideas de los cineastas Jacques Aumont, tratando de teorizar sobre la unidad de la imagen-forma, encuentra y reconoce en su reflexión que cada obra debe inventar sus propias leyes para la forma, e incluso sus "procedimientos" para "formular de manera adecuada la relación que mantiene con la realidad" (Aumont, 2004: 69). El propio André Bazin, como recoge Gilles Deleuze, es consciente de esta noción de que el lenguaje del cine siempre está por hacer, de que la siguiente película siempre pueda traer una novedad en el decir (Deleuze, 1986: 11) y, con ello, hemos de añadir, una nueva forma a aprehender y a aprender ese oficio, lo cual provoca, por un lado, que la sistematización de procesos quede siempre abierta y tangente. Tangente, por un lado, a la nueva delimitación y codificación de ese lenguaje en constante reformulación y, por otro lado, a la dependencia y el compromiso por "lo ya hecho", ya que la teoría del cine no puede, en ningún caso, dejar de entender el cine, en cierta medida, como las películas que ya han sucedido y que, por esta característica que apuntamos, quedan automáticamente desbordadas y anticuadas.

Efectivamente, cada nueva película terminada se convierte inmediatamente en antigua, pero, a la vez, en sustrato de las siguientes por venir. Cualquier cineasta al que se le permitiera entrar en la sala de montaje durante un par de horas tras el día de estreno en las salas de cine estaría seguro de poder hacer un par de cambios que le otorgarían, según su renovada visión, algún punto más de fuerza y expresividad a la obra. Esta certeza, sin embargo, tampoco debe confundirnos y llevarnos a pensar esta cuestión en términos de estilo. En la relación de la realidad con su expresión a través del cine, no solo podemos encontrar infinitas maneras para esa expresión, sino que, en cada nuevo intento, podemos encontrar, a nivel de contenido y de significado - ergo del lenguaje-, una nueva realidad, algo hasta entonces no dicho. Definitivamente no podemos plantear, no hay una buona maniera ${ }^{4}$ de hacer cine.

La apreciación al respecto, desde la perspectiva de la psicología, concretamente de Jean Mitry, reafirma esta postura: "Cada obra nueva vuelve a cuestionarlo todo. Lo cual no quiere decir que la armonización sea imposible, sino que no puede referirse a ninguna regla, a ninguna ley". Sin embargo, añade el teórico y cineasta francés: "Solo puede ser arbitraria y eminentemente subjetiva" (Mitry, 2002: 161). En ese subjetivismo puede encontrarse también el carácter tácito con el que se aplican y desarrollan los procesos de trabajo en muchos ámbitos de la producción cinematográfica, imprimiendo esta circunstancia en una práctica profesional tan

4 Tomamos el término del texto citado de Luis Alonso, en el que el autor propone la misma idea, pero sustentada en motivos de corte más ontológico y cultural. Para profundizar en esta perspectiva, ver Alonso (2013). 
tecnificada, hiper-programada, presupuestada y planificada, un altísimo componente de fe en la labor de los cineastas. ${ }^{5} \mathrm{Y}$ sobre la fe es difícil construir trasvases entre teoría y práctica.

Insistiendo en la perspectiva psicológica y filosófica, la idea de sustentar una praxis fílmica ${ }^{6}$ donde se reúnan el saber y el hacer encuentra una correlación de interesantes derivaciones didácticas en la perspectiva fenomenológica de Maurice Merleau-Ponty. En El cine y la nueva filosofía, el autor discutió los parámetros fenomenológicos del cine como "Gestalt temporal". La filosofía gestáltica más básica tiene una evidente proyección en los modos de crear el cine: el trabajo segmentado, especializado y compartimentado de los diversos departamentos implicados en cualquier producción cinematográfica debe ser integrado y recreado en virtud de una nueva, diferente y superior realidad ontológica que es el filme y que es la unidad de sentido final de unos procesos especializados que se rigen por otras lógicas operativas. Según Stam, partiendo de Merleau-Ponty, la operación de la suma de Gestalt más fenomenología existencial puede dar como resultado una base psicológica para las estructuras básicas de la experiencia cinematográfica como experiencia mediada de ser-en-elmundo, como una "Gestalt temporal” cuyo palpable realismo sería aún más exacto que el del mundo real (Stam, 2001: 101). Coincidimos con el autor norteamericano en que las obras capitales de Jean Mitry sobre psicología y estética cinematográfica presentan una fenomenología similar a esta.

Pensando en Robert Bresson y aplicando la idea kantiana sobre la idea y el destino de la idea, Aumont otorga al cine la capacidad de "inventar conceptos", y recopila en su obra citada una serie de cineastas que entendieron el cine, como explicitaría Jean Epstein, como una "máquina de pensar" (Aumont, 2004: 20, 44). En contra de las bases posteriores del estructuralismo y la semiología, el psicólogo alemán Hugo Münsterberg había argumentado, antes incluso que Eisenstein, que lo que el cine realmente significaba como construcción expresiva era la reconfiguración de la realidad tridimensional de acuerdo con esas "leyes del pensamiento" (Stam, 2001: 46). Si bien este autor se sintió también atraído por las aplicaciones de la psicología a la incipiente narrativa cinematográfica de las primeras dos décadas del siglo $\mathrm{XX}{ }^{7}$ la idea más interesante que conecta el entendimiento de la construcción fílmica con la formación del pensamiento consciente es la de la "distancia" del cine respecto a la realidad física. A diferencia, sin ir más lejos, del teatro, esa distancia interpuesta por el registro fílmico frente a la realidad material representada, ejerce como puente directo hacia la esfera mental y la (auto) generación del placer estético. Según el autor, el cine libera así al mundo palpable del peso del espacio, el tiempo y la causalidad, "dotándolo de las formas de nuestra propia conciencia" (Stam, 2001: 46). No nos hallamos tan lejos, habiendo partido del distanciamiento consciente de los enfoques semiológicos, de la idea del "significante imaginario" de Christian Metz, según la cual, es precisamente esa naturaleza "imaginaria" del significante fílmico la que lo convierte en el poderoso catalizador de emociones y de proyecciones psicológicas

5 Aumont llega a establecer que hay solo dos perspectivas teóricas: la mágica o la religiosa. Aumont, op. cit., p.75.

6 Consideraremos el término "praxis fílmica" en el sentido planteado por Alonso (2014), como integrador de la labor práctica y teórica, así como de los sujetos creadores y receptores de la obra fílmica.

7 Con ideas tan sugerentes como la de que la selección que el cineasta hace de lo que es significativo y consecuente convierte el "caos" de las impresiones sensibles en el "cosmos" del cine. (Stam, 2001: 45). 
y emocionales que caracteriza la expresión cinematográfica (Metz, 2011). ${ }^{8}$ En esta línea de reflexión, ¿podemos plantear como perspectiva didáctica y epistemológica la idea de que enseñar a hacer cine sea, en realidad, y de manera sustancial, enseñar a pensar?.

\section{Praxis fílmica, lugar de encuentro}

La elaboración del pensamiento abstracto es una cuestión en crisis en los sistemas educativos actuales de manera general y mucho más allá de nuestro ámbito de estudio. Sin embargo y, precisamente por ello, creemos necesario indagar en esta dirección: si estamos insinuando y animando desde estas páginas a plantear la perspectiva psicológico-filosófica de la formación del pensamiento en la integración de la teoría y práctica cinematográfica y su fundamental derivación en la didáctica cinematográfica, ¿qué tipo de propuestas podemos encontrar parcialmente orientadas en esta dirección, que apunten hacia una teoría integradora de lo que llamamos praxis fílmica? Esbozaremos algunas ideas al respecto, tratando de abordar a través de ellas las principales preocupaciones planteadas.

De manera muy sencilla y basada en un enfoque teórico-práctico, Alain Bergala propone en su interesante y accesible obra La hipótesis del cine, por un lado, una interesante idea general sobre el enfoque pedagógico y, por otro lado, una muy concreta idea puramente didáctica sobre cómo trabajar sobre la construcción del pensamiento. La primera idea, con ecos de una gran discusión potencial de fondo, establece que no es necesario establecer pedagogías diferenciadas para la teoría y el análisis y para la práctica cinematográfica. Considera el teórico y cineasta francés que puede haber una pedagogía centrada en la creación tanto cuando se miran las películas como cuando se realizan. Habla de una "pedagogía generalizada de la creación" (Bergala, 2007: 38), término que bien puede encajar en la idea de "praxis fílmica" trabajada por Alonso (2014) y que nosotros tomamos como marco teórico a completar.

La segunda idea-propuesta extraída de esta obra presenta, transitando hacia lo concreto, unas condiciones que consideramos de especial interés en nuestra reflexión, ya que el autor sugiere el establecimiento teórico de una serie de operaciones mentales bien definidas, unidas directamente a procesos de operaciones materiales en el proceso de la creación fílmica. Partiendo de la noción del plano como factor de aproximación al cine, esta noción pone en juego, instrumentalmente, la mayoría de las elecciones que intervienen real y simultáneamente en la creación cinematográfica: ¿dónde empezar y dónde acabar el plano? ¿cómo tal o cual gran cineasta ha hecho un uso personal del plano? (Bergala, 2007: 122-123) ${ }^{9}$. Observamos en esta doble pregunta que formula el autor la coherencia y la integración en esa doble tangencia de la que hablábamos con anterioridad y que genera una tensión

8 Stam considera que Marshall McLuhan estaba sugiriendo algo parecido cuando situaba en contraposición medios “cálidos" frente a medios "fríos". En Stam, op. cit., p. 146.

9 En el texto incluye, algo más adelante, el estudio de la perspectiva histórica en cuanto a la evolución del concepto plano, lo cual puede contribuir también a la integración didáctica de las perspectivas teóricas tradicionales. 
que consideramos necesaria para poder hacer converger las propuestas didácticas histórica y coyunturalmente distanciadas.

Se plantea el plano como una iniciación a la creación a partir de una toma de conciencia de todas las elecciones que implica "hacer un plano". Es importante recalcar cómo esta sencilla postulación teórica supera, de una tacada, la incongruente y extendida obsesión por hacer del alumno inexperto creador de una película completa en su primera iniciación a la formación práctica. En esa toma de conciencia, Bergala propone un simple esquema teórico de tres operaciones mentales a realizar y/o analizar, antes de hacer lo propio, de manera coherente, con las operaciones técnicas. Estas tres operaciones mentales serían "elegir", "disponer" y "atacar". Elegir hace referencia a escoger algunas cosas en lo real, entre otra posibles. Disponer, a situar las cosas unas en relación con las otras, y atacar, básicamente a decidir el ángulo o el punto de ataque sobre las cosas elegidas y dispuestas. ${ }^{10}$ Estas tres operaciones mentales no corresponderían a momentos específicos ni cronológicos de la cadena, pero sí serían combinables en cada momento de esta. Su simplicidad no impide que su elocuencia y evidencia establezcan, de inmediato, diálogos con otras ideas de corte teórico, ${ }^{11}$ al mismo tiempo que, como el propio Bergala hace en su texto, sean de una sencillísima aplicación a cualquier ejemplo práctico de las múltiples rutinas de la creación cinematográfica.

Entiende Bergala que, en el acto de poner en escena un plano de manera concreta, todo cineasta oscila sin cesar entre una exigencia de disposición y una pulsión de ataque y que, de esta suerte de contradicción creadora, surge el plano realizado, definitivo, como resolución en acto, dialéctica (Bergala, 2007: 132). Las elecciones, disposiciones y ataques se producen sobre una realidad que se resiste en las múltiples formas en las que el cine la contempla y reproduce, y de esa tensión entre lo que se muestra y lo que se esconde, entre, en palabras del fotógrafo Alberto García Alix, "un algo que quiere salir y un algo que no quiere salir", ${ }^{12}$ el cineasta construye la unidad básica del plano, que así se concreta, en esa relación dialéctica, estableciendo el punto de vista del autor. O, en palabras de Jacques Aumont: "la imagen cinematográfica, en cuanto imagen artística, nace de la paradójica conjunción entre querer y no querer, entre la intencionalidad artística y la sumisión al estar-allí, en el mundo." (Aumont, 2004: 62).

En este universo de poéticas ${ }^{13}$, Bergala se muestra, lógicamente, preocupado por la sistematización pedagógica de ideas como que, en un plano, sea más sencillo producir determinado sentido narrativo que lograr atrapar un vestigio de vida (Bergala, 2007: 16), lo que nos devuelve —o nos asienta - al terreno de la fenomenología, donde su precursor Edmund Husserl nos señala, en la misma idea, un gran problema y su posible solución aplicada a nuestro campo, cuando afirma

10 Para una amplia explicación de la propuesta y los ejemplos que el autor expone divididos en las fases de rodaje, montaje y mezclas, ver Bergala, 2007: 131-132.

11 Pensamos, por ejemplo, en cómo establece Pier Paolo Pasolini la idea de la "inevitable subjetividad en la primera operación del autor de cine: la elección de los im-signo en el caos de la realidad” (Pasolini, 1970: 20), o las ideas expresadas por Víctor Erice, en el análisis de las películas primigenias de los hermanos Lumière, de la necesaria abolición de las barreras taxonómicas entre cine de ficción y cine documental. (Erice, 2015).

12 En el largometraje documental La línea de sombra (Nicolás Combarro, 2017). Como apunta Robert Stam, "En ocasiones, la tensión y la ambigüedad son la clave de todo." (Stam, 2001: 20).

13 Antonioni consideraba que la observación de la realidad solo era posible poéticamente. (Antonioni, 2002: 259). 
que "las cosas del mundo físico pueden no existir, pero ninguna vivencia de una persona puede dejar de existir." (Quintana, 2003: 117). La intencionalidad del autor cinematográfico se convierte así — podría parecer evidente, pero no lo es en los estudios - en el hilo directo del pensamiento del ser, ya que el punto de partida de la ontología fenomenológica no es ni la idea de "yo soy", ni la de "el mundo es", sino el establecimiento de una correlación intencional entre el ser y la realidad empírica situada en el seno de toda experiencia. La cámara y el micrófono caben ser establecidos como instrumentos válidos y útiles para, no solo capturar la huella mecánica del mundo, sino para comprenderlo en función de las - mediatizadasintenciones expresivas de un cineasta. En sintonía con esta idea, Àngel Quintana aúna intencionalidad y consciencia interpretante como factores necesarios y pertinentes en la ecuación de la comprensión del fenómeno cinematográfico (Quintana, 2003: 117). Vamos llegando poco a poco a ese territorio común donde el hacer y el saber son parte de una misma actividad que llamamos praxis fílmica, y en la que se empieza a responder a cuestiones como las que planteaba Rafael Tranche en las primeras páginas de este trabajo: "elucidar las claves formales o los procesos de sentido que operaron en su gestación y conforman su lectura”.

\section{Hacia el cine por el cine}

El triunfo auténtico del maestro, pocas veces reconocido, es ser refutado, superado por el descubrimiento del discípulo (...) No hay oficio más privilegiado. Despertar en otros seres humanos poderes, sueños que están más allá de los nuestros; inducir en otros el amor por lo que nosotros amamos; hacer de nuestro presente interior el futuro de ellos. (Steiner, 2003)

Una tercera idea aportada por Alain Bergala en su obra citada nos sirve para conducirnos hacia el necesario desenlace de nuestra reflexión: la imbricación entre práctica y teoría en la perspectiva docente. Reflexiona el autor francés sobre la dicotomía entre enseñanza e iniciación, partiendo de la constatación de que no es posible el acercamiento real al arte sin el aprendizaje de la atención (Bergala, 2007: 67). De una tacada, el autor hace partícipe y complemento necesario un término del otro, reconduciendo, muy adecuadamente a nuestro parecer, la necesidad del punto de la educación desde el pensamiento (aprendizaje) hacia la experiencia estética práctica (iniciación). "No hay acercamiento al arte sin aprendizaje de la atención (...) No hay amor por el arte sin elección de objeto (...) A partir de ahí, habrá que dejar que la necesaria extrañeza de la obra de arte haga su lento camino por sí sola" (Bergala, 2007: 109). Estas ideas conjugadas nos hacen pensar en las descripciones que algunos grandes cineastas nos han proporcionado sobre la imbricación entre sus ideas basadas en la observación y su transformación en sustancia expresiva fílmica a través de su confrontación con las acciones básicas de la práctica. Michelangelo Antonioni lo expresa así: "He de mirar a través de la cámara para ver si lo que he escrito en la cámara vale o no. (...) lo llaman improvisación, pero no lo es; es sencillamente hacer una película. Todo el trabajo realizado antes son apuntes" (Antonioni, 2002: 214).

Con la idea de la iniciación a la creación partiendo del aprendizaje de la atención y de la elaboración de operaciones mentales sustentadas en las ideas hasta aquí esbozadas, no nos resistimos a plantear un ejemplo de dispositivo práctico de creación a partir del cual poder plantear la generación de contenidos de interés y 
sistematización teórica. La idea se podría contemplar a partir del conocido concepto del making of, tan extendido y conocido en el mundo comercial de la industria cinematográfica. Sugiere Josep María Català que un director o una directora que reflexione sobre el cine desde la propia práctica cinematográfica es un fenómeno cultural nuevo y necesario (Català, 2001: 25). Sabemos que hay eminentes cineastas que ya han abordado esta tarea, pero - como muy bien sabe y sugiere Català- - lo que es necesario poner en juego es un sistema, una metodología, una forma de hacer extendida y coherente para su aplicación docente y cultural.

En este caso, pensamos en la elaboración, por parte del estudiante-iniciante, o bien por parte del investigador experimentado, o del cineasta ensayista, de una película sobre la creación de una película. Una película-acercamiento cuyo objetivo no es describir, mostrar, dejar testimonio sobre los entresijos de la realización de la película objeto de observación, sino, en primer lugar, descubrir los mecanismos que guían en el proceso de producción y, en segundo - y esto es capital- encontrar la forma más eficaz de comunicar a través de la nueva película ese proceso. Más que un making of, se trataría de una película-ensayo que experimenta sobre el lenguaje sobre un tema muy concreto: el proceso de creación de la película monitorizada. Sobre estas dos fases que hemos diferenciado y ordenado en cuanto a la voluntad de contenido y forma de este ejercicio práctico, podemos proyectar la idea de Roberto Rosellini, reiterada por multitud de creadores cinematográficos, según la cual, el cineasta siempre debía comenzar su proceso con una actitud pasiva, absorbente, observadora, para a continuación transformarse esta en una actitud activa, creadora ${ }^{14}$.

Esta propuesta, aparentemente difícil de sistematizar, encierra sin embargo una de las premisas fundamentales apuntadas por Bergala, y que consideramos capital para enfrentar la cuestión a estudio: nos referimos a la reunión entre el necesario despliegue de una estrategia mental de observación, de organización de ideas y objetivos de aprendizaje y conocimiento, con la iniciación práctica en las formas de la escritura fílmica aplicada. Roberto Rosellini consideraba que la contemplación se prepara en todos los planos, no en uno en particular (Rosellini, 2000: 24). Para ello, hemos de liberarnos, siguiendo a Bergala, de la recurrente aproximación al filme exclusivamente como texto productor de sentido (el autor ha elegido este ángulo o este encuadre para significar tal cosa). Concluye el autor francés que, para él, lo decisivo "no es ni siquiera el 'saber' del docente sobre el cine, sino la manera como se acerca a su objeto".

Desde nuestra perspectiva, si, como decía Jacques Rivette, el método que se utiliza para rodar una película es siempre el verdadero tema (Rosellini, 2000: 28), en este caso el cineasta-estudiante-investigador-iniciante se enfrentaría a la simple pero compleja y - posiblemente- reveladora tarea de tener que construir una película cuyo tema es descubrir la relación entre tema y proceso de creación de otro cineasta (objetivos de aprendizaje). Un descubrimiento para el que David Bordwell aporta una posible clave de acceso, pensando en las películas de corte artístico o autoral. Según Bordwell, en los rasgos y dispositivos narrativos más marcadamente estilísticos de la labor desplegada por los cineastas — añadimos nosotros que ya sea de forma consciente o inconsciente-, se puede apreciar siempre una suerte de

14 Sin ir más lejos, mientras se escribe este artículo, la cineasta argentina Lucrecia Martel se ha dirigido exactamente en estos términos a los alumnos de la Escuela de Cinematografía de la Comunidad de Madrid en un seminario celebrado en Madrid los días 12 y 13 de enero de 2018. 
comentario o, mejor dicho, meta comentario que, debido a la autoconciencia que este tipo de cine suele conllevar, puede revelar, en términos de coherencia principal, las relaciones entre los temas y contenidos de la obra y las formas y decisiones sobre las que se ha construido (Bordwell, 2003: 42-43). Profundizando en esta idea, Michelangelo Antonioni afirmaba que el problema técnico, en la práctica, no existe. Consideraba el cineasta italiano que "si hay estilo, impregna la técnica. En cambio, si no hay estilo, no existe el problema." (Antonioni, 2002: 195).

En esta línea, el proyecto que sugerimos, dirigido desde esta perspectiva pedagógica, podría arrojar datos de gran interés para profundizar en la sistematización y teorización sobre el trabajo de los cineastas, al mismo tiempo que renueva e integra, dentro del proceso mayor de reunión de las ideas y las prácticas del cine, el trabajo de un nuevo cineasta que se inicia y se forma desde el aprendizaje y la responsabilidad de la creación. $\mathrm{Si}$, como se ha repetido en infinidad de textos, el corazón de la creación no pertenece al mundo de lo visible, la mediación del cine sobre esa creación, cuyos brazos, manos y piernas sí que son bien visibles mientras trabajan, cuya voz es bien audible mientras anima, rectifica, se lamenta, pide, duda, aclara..., no solo puede ser capaz de tornar visible ese corazón palpitante y escondido, sino que está en posición de, una vez comprendido, sentido, y entendidos sus efectos en el resto de los hombres, poder ser representado para nosotros, los interesados en ese proceso de creación. El resultado será una interpretación del objeto-película estudiado por el segundo cineasta (el que observa trabajar al primero). Una de las muchas posibles, desde luego. Como sabía Roberto Rosellini, no puede establecerse una pedagogía de la verdad (Rosellini, 2000: 22). La búsqueda de la verdad es una herramienta de trabajo y un horizonte, tanto de la creación como de la filosofía, ciencia del cuestionamiento y la generación de preguntas. En el arte, la verdad está en la experiencia estética de cada espectador. El objetivo de este tipo de propuesta es, insistimos, la reunión de aprendizaje mental e iniciación a la praxis fílmica aplicada, sin desviar el objeto de estudio, y en busca de la generación de materiales y procesos de trabajo donde teoría y práctica coexistan de manera necesaria y retroalimentada.

\section{Ni ellos ni nosotros. Conclusiones a partir de un perfil}

Finalmente, completamos nuestra reflexión planteando la cuestión, muy posiblemente secundaria, pero de urgente revisión, sobre la figura del cineasta en términos de esta dicotomía entre práctica y teoría. O más bien las figuras, en plural, que no acaban de converger y que, entendemos, no está de más replantear en busca de una adecuada aplicación de los trabajos a reunir como los sugeridos en estas páginas. La pregunta que late al fondo de todo lo expuesto tendría posiblemente dos cuestiones encadenadas en su formulación. En primer término, nos cuestionaríamos si es necesario pensar en un perfil profesional en concreto para poder abordar esta integración entre teoría y práctica. En segundo término, si ese perfil es un modelo por instaurar, por inaugurar, y si procede intentar esbozar una descripción de ese modelo profesional. Josep María Català apunta un claro perfil, ejemplificado en la figura de Rafael Tranche, cuando le toca hacer una evaluación sobre el texto de este en el que aborda los procesos de creación fílmica (Tranche, 2015). Habla Català de una necesaria caracterización del autor que mezcle: 
Los vectores que se precisan para lograr de forma efectiva esa necesaria combinación: por un lado, la experiencia en la práctica cinematográfica, es decir, el haber dirigido él mismo; por el otro, el gusto por y la capacidad para la teoría, que posibilita encontrar el significado de la práctica, tantas veces glorificada en el vacío; $y$, finalmente, ser docente, que ejercita la facultad de exponer las ideas con sencillez. (Català, 2015: 158)

Parece una descripción adecuada, y sin duda el profesor Tranche es una figura más que pertinente para trabajar sobre esta cuestión. Sin embargo, el perfil descrito por Català — absolutamente certero y enriquecedor a la hora de afrontar el monográfico que está comentando- no deja de estar constituido por adición, a falta quizá de un territorio de integración, de un vínculo o elemento que, más allá de la transversalidad de la propia actividad fílmica como tema - ya que raramente el cineasta que está dirigiendo una película está, conscientemente, reflexionando sobre su propia metodología-, caracterice a esta especie de cineasta total teórico-práctico que parecemos andar persiguiendo.

En esa vocación podríamos fácilmente situar nuestra mirada sobre los grandes cineastas que, a través de una poética propia muy marcada, no solo han desarrollado a la vez grandes películas y extensos textos teóricos o ensayísticos (y poéticos, en el sentido aristotélico del término) al respecto, sino que además han trabajado en la práctica con esa conciencia y esa aplicación ya poiética de sus propios principios teóricos. Nos referimos evidentemente a los conocidos casos de Andréi Tarkovski, Sergei M. Eisenstein, Pier Paolo Pasolini, Robert Bresson, Eric Rohmer, o incluso a aquellos cineastas que, sin haber redactado tratados teóricos de más peso, sí han expresado en diferentes espacios de reflexión, interesantes y reveladoras ideas teóricas que, además, podemos observar aplicadas en sus propias obras. Son los casos de autores como Víctor Erice, Jean-Luc Godard, Ingmar Bergman o Roberto Rosellini entre otros. ${ }^{15}$ Sin duda interesantes, por momentos apasionantes, estos trabajos no dejan de sustentarse en los propios intereses y limitaciones de cada uno de los cineastas en cuestión, en cuyos textos, si bien hay una profunda preocupación por las capacidades expresivas del medio y sus componentes morales, y, desde la perspectiva pedagógica, quizá su aplicación se limite en cierta manera a su calidad de valiosísimos casos de estudio concretos, valiosos y, eso sí, asumibles por parte de cualquier cineasta, con el riesgo - habitual en la práctica artística- de aprender y dedicarse a hacer películas "como las hace este o aquel", derivando la operación en ejercicio estilístico. Huyamos pues de la búsqueda de perfiles a posteriori que acaben por señalar injustamente quién puede estar más o menos capacitado para abordar una cuestión que consideramos debe enfocarse de manera mucho más - literalmenteradical.

En ese sentido, y tornando nuestro discurso hacia sus conclusiones finales, retomamos la perspectiva pedagógica, alumbrada ahora también por la cuestión del perfil del cineasta-teórico-docente puesta en juego, para plantear que es, concretamente, en el tipo de aproximación al objeto cinematográfico que se presente a los estudiantes, desde donde se puede incidir en la superación de ese abismo invisible que separa extrañamente los mundos de la práctica y la teoría en los estudios de cine. Muchos de esos estudiantes que se acercan a estos estudios lo hacen impulsados por

15 Un interesante compendio y revisión desde el punto de vista teórico de este tipo de ideas lo encontramos en la obra citada de Jacques Aumont. 
una vocación práctica, pero el paso que están dando para ello es una incorporación al mundo académico. Esta circunstancia no pude ser vista por nosotros, docentes, investigadores, cineastas, más que como la oportunidad perfecta, incluso única, para echar decididamente abajo la idea del ellos y el nosotros. La dicotomía entre teoría y práctica, entre cineastas teóricos y prácticos. No se trata tanto de adquirir nosotros ese perfil profesional ideal que acapare la sabiduría necesaria para luego transmitirla, como de reivindicar la consustancialidad de ambos mundos, pero no, si se nos permite, ontológicamente, sino contextual y aplicadamente, en el mundo académico, en la universidad. Ambos aspectos son consustanciales y necesarios en nuestro campo de actuación, pero, como decíamos al principio, entre ambos extremos asistimos a un silencioso vacío que es necesario enmendar, y que no puede ser remediado desde el sacrificio del ellos o del nosotros, dondequiera que quiera situarse la otredad. Nuestros alumnos no son ni unos ni otros cuando llegan a las aulas. Son, pueden ser, los cineastas. Los nuevos hombres y mujeres del cine. De todo él. A esta primera conclusión general, añadiríamos, de manera más concreta, la necesidad de incidir en la formación del pensamiento abstracto aplicado a la labor práctica cinematográfica, incidiendo en la necesaria implementación de sistemas de operaciones mentales concretas y analizables para poder poner en relación un universo subjetivo, de lenguaje abierto y multidimensional, con su comprensión, análisis y aprendizaje, y desde una perspectiva académica en clave creativa.

Finalmente, nos parece remarcable la necesidad evidente de lograr la conexión entre los dos aparentes polos de nuestro terreno profesional a través de una intervención mutua de la teoría en la práctica y viceversa, las dos caras de lo que venimos denominando como praxis fílmica. Comenzar a investigar posibles metodologías de aplicación de procesos intelectuales a la realización de películas, como el esbozo del making of deconstructivo y didáctico que hemos planteado, así como su reverso, hacer películas sobre los procesos de creación hacia la generación de materiales teóricos cinematográficos, pueden ser caminos dignos de explorar en la superación del incomprensible divorcio en el que hoy viven, bajo el mismo techo de los estudios académicos, teoría y práctica fílmicas.

\section{Bibliografía}

Alonso, L. (2013). "El saber hacer del proceso fílmico: del cineasta al filmólogo". Archivos de la Filmoteca, 71, abril 2013.

Alonso, L. (2014). "Peliculeros zarandeados en la selva de las cosas y los signos". Las distancias del cine (Intersecciones). Shangrila Derivas y Ficciones Aparte, 22, noviembre 2014.

Antonioni, M. (2002). Para mí, hacer una película es vivir. Barcelona: Paidós.

Arijon, D. (2003). Gramática del lenguaje audiovisual. Andoain: Escuela de Cine y Vídeo.

Aumont, J. (2004). Las teorías de los cineastas. La concepción del cine de los grandes directores. Barcelona: Paidós.

Benet, Vicente José (1999). La Cultura del Cine. Barcelona: Paidós.

Bergala, A. (2007). La hipótesis del cine. Pequeño tratado sobre la transición del cine en la escuela y fuera de ella. Barcelona: Laertes.

Bordwell, D. (2003). "Authorship and Narration in Art Cinema”. En Virginia Wright Wexman (ed.), Film and authorship. Nueva Jersey y Londres: Rutgers University Press. 
Bordwell, D. y Thompson, K. (1995). El arte cinematográfico. Barcelona: Paidós.

Bresson, R. (1997). Notas sobre el Cinematógrafo. Madrid: Ardora.

Brown, B. (2008). Cinematografía. Teoría y práctica. Barcelona: Omega.

Burch, N. (1970). Praxis del Cine. Madrid: Fundamentos.

Camino, J. (1997). El Oficio del Director de Cine. Madrid: Cátedra.

Català, J. M. (2001). La puesta en imágenes. Conceptos de dirección cinematográfica. Barcelona: Paidós.

Català, J. M. (2015). Reseña "Del papel al plano. El proceso de la creación cinematográfica". Secuencias, 42.

Chion, M (2003). El Cine y sus Oficios. Madrid: Cátedra.

Ciller, C. y Palacio, M. Producción y desarrollo de proyectos audiovisuales. (2016). Manuel. Madrid: Síntesis.

Costa, A. (1991). Saber Ver el Cine. Barcelona: Paidós.

Deleuze, G. (1986). La imagen-tiempo. Estudios sobre el cine 2. Barcelona: Paidós.

Eisenstein, S. M. (2017). Teoría y técnica cinematográficas. Madrid: Rialp.

Erice, V. (2015) Seminario Documental y ficción. Madrid, 19-22 enero 2015.

Ferrer, A. at ali. (2006). Primum videre, deinde philosophari. Valencia: Institució Alfons el Magnànim.

Gombrich, E. H. (1997). Gombrich esencial. Textos escogidos sobre arte y cultura. Barcelona: Random House Mondadori.

Katz, S. D. (2005). Plano a Plano, de la idea a la pantalla. Madrid: Plot,

Martel, L. (2018). Seminario Creación y experimentación sonora. Madrid: ECAM, 12-13 enero 2018.

Metz, C. (2001). El significante imaginario. Barcelona: Paidós.

Mitry, J. (2002). Estética y psicología del cine 1. Las estructuras. Madrid: Siglo XXI.

Mitry, J. (2002). Estética y psicología del cine 2. Las formas. Madrid: Siglo XXI.

Pasolini, P. P. y Rohmer, E. (1970). Cine de poesía contra cine de prosa. Barcelona: Anagrama.

Quintana, À. (2003). Fábulas de lo visible. El cine como creador de realidades. Barcelona: Acantilado.

Rabiger, M. (2009). Dirección cinematográfica, técnica y estética. Barcelona: Omega.

Rancière, J. (2002). El Maestro Ignorante. Barcelona: Laertes.

Rosellini, R. (2000). El cine revelado. Barcelona: Paidós.

Sarris, A. (1969). Entrevistas con Directores de Cine. Madrid: Emesa.

Schenk, S. y Long, B. (2012). Manual de Cine Digital. Madrid: Anaya.

Sennett, R. (2009). El artesano. Barcelona: Anagrama.

Stam, R. (2001). Teorías del cine. Una introducción. Barcelona: Paidós.

Steiner, G. (2004). Lecciones de los Maestros. Madrid: Siruela.

Tarkovski, A. (2002). Esculpir en el tiempo. Rialp: Madrid.

Tirard, L. (2003). Lecciones de Cine. Barcelona: Paidós.

Tirard, L. (2006). Más Lecciones de Cine. Barcelona: Paidós.

Tranche, R. R. (2015) Del papel al plano. El proceso de creación cinematográfica. Madrid: Alianza. 